\title{
O COMPLEXO E NECESSÁRIO EXERCÍCIO DE OBJETIVAR A INVESTIGAÇÃO EM EDUCAÇÃO
}

\author{
THE COMPLEX AND NECESSARY EXERCISE OF \\ OBJECTIFYING RESEARCH IN EDUCATION
}

\section{EL EJERCICIO COMPLEJO Y NECESARIO PARA OBJETIVAR LA INVESTIGACIÓN EN EDUCACIÓN}

\begin{abstract}
ALVES, M. G.; AZEVEDO, N. R.; GONÇALVES, T. N. R. Educational theory informing educational research: scenarios and lines of flight. Caparica: UIED/FCT, Universidade Nova de Lisboa, 2013.
\end{abstract}

Camila Ferreira da Silva Lopes ${ }^{\mathrm{I}}$

IUniversidade Nova de Lisboa - Portugal. E-mail: ferreira.camilasilva@ gmail.com

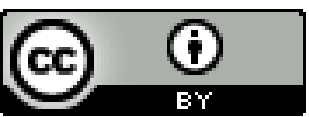

Educação: Teoria e Prática, Rio Claro, SP, Brasil - eISSN: 1981-8106

Está licenciada sob Licença Creative Common

Os esforços de autorreflexão vêm marcando o desenvolvimento das diferentes áreas do conhecimento e geraram [e ainda geram] trabalhos que, de um lado, buscam apresentar e discutir questões epistemológicas, históricas e o próprio métier do pesquisador e, de outro, visam mapear os caminhos que cada domínio tem percorrido com base na caracterização das 
produções, tendências temáticas, metodologias, principais referências etc. Tais trabalhos irradiam-se também pelo domínio da Educação e vêm possibilitando um conhecimento cada vez mais aprofundado acerca das condições de produção da própria investigação educacional $^{1}$.

A obra que aqui ganha uma recensão crítica, Educational theory informing educational research: Scenarios and lines of flight, publicada em dezembro de 2013, situa-se, do ponto de vista do empreendimento que realiza, neste panorama de exercícios reflexivos que procuram objetivar a própria área da qual se faz parte.

Organizada pelas pesquisadoras Mariana Gaio Alves, Nair Rios Azevedo e Teresa Gonçalves- uma socióloga, uma psicóloga e uma filósofa, de formação inicial, todas com doutoramento na área da Educação e trabalhos nesta área há mais de uma década -, a obra em questão reúne investigadores de diferentes nacionalidades e com linhas de interesses distintas (além das organizadoras, estamos falando de Gert Biesta, Antonio Bernal Guerro e Joaquín García Carrasco) e chama atenção, dentre outros elementos aos quais deteremo-nos mais adiante, pelo motivo em torno do qual estes pesquisadores reuniram-se: a necessidade de refletir sobre o cotidiano das práticas acadêmicas na área da Educação. Os textos que compõem o livro ganharam materialidade a partir das experiências pedagógicas e científicas que o trabalho no ensino superior proporcionou aos autores em seus respectivos países, sobretudo nas suas relações com os estudantes da pós-graduação.

O trabalho de orientação permitiu a estes autores atentarem para a "luta" que os estudantes de doutorado travam no processo de desenvolvimento de suas próprias investigações: emergem de tais lutas questões relativas ao status disciplinar da Educação bem como ao lugar apropriado para a teoria e epistemologia e ainda às tomadas de decisões teórico metodológicas mais adequadas para cada investigação. As reflexões tecidas ao longo dos quatro capítulos do livro foram, pois, fabricadas a partir de uma "herança", no âmbito da produção acadêmica, relacionada à análise do próprio processo de investigação, de um lado, e também a partir de uma objetivação da atualidade revelada pelos desafios cotidianos que as práticas de desenvolver, orientar e julgar novas investigações acarretam, de outro. Pode-se afirmar, dessarte, que o fio condutor da discussão centra-se no papel e utilização da teoria na

\footnotetext{
1 Sabendo que existem inúmeros trabalhos que cumprem este exercício autorreflexivo sobre o campo da Educação, citamos alguns na tentativa de exemplificar como tal exercício foi levado a cabo por diferentes países, incluindo o Brasil: Estrela (1992), Berger (1992), Gatti (2002), Biesta (2011), Furlong e Lawn (2011).
} 
pesquisa educacional. Para tal, as especificidades e a complexidade que acompanham a trajetória de desenvolvimento de um campo multi-referencial, que se formou com base nos contributos de áreas do conhecimento bastante distintas entre si, ganham destaque.

São quatro os capítulos que formam o livro e buscam apresentar perspectivas e abordagens diversas para a problemática em torno da função da teoria no desenvolvimento da própria área da Educação, nomeadamente: Theory and research in education: the case for pragmatism de Gert Biesta; Theorizing education and educating researchers: one experience at UIED/FCT/UNL, de Teresa N. R. Gonçalves, Nair R. Azevedo e Mariana Gaio Alves; Education theory and the education of researchers at the University of Seville: analyses of contentes of a doctoral programme os the department of theory and history of education and social pedagogy de Antonio Bernal Guerrero; e Educational theory: an open Project for mind and culture de Joaquín García Carrasco.

Há que se destacar, em caráter complementar e antes mesmo de analisar aqui capítulo a capítulo, a importância da apresentação da obra, intitulada Theorizing education: Introducing a conversation e assinada pelas próprias organizadoras da obra, pois as dezesseis laudas dedicadas a introduzir o livro aos leitores vão além de um trivial epítome dos capítulos. Arriscaria dizer que esta apresentação merece atenção por parte de todos aqueles que pesquisam no espaço científico da Educação, posto que cumpre uma árdua tarefa de caracterização de tradições e tendências ligadas aos processos de cientifização desta área - as tradições francesa, alemã e angloamericana ganham destaque neste debate, sobretudo no que tange aos esforços de cientifização da pesquisa em Educação levados a cabo nestes países e nas influências que exerceram nos processos de autonomização relativa desta área em vários países do globo.

Esta tarefa de caracterização das tendências acaba por constituir-se em antesala adequada aos capítulos que a seguem, uma vez que é capaz de suscitar um debate acerca das homogeneidades e heterogeneidades que marcam a Educação como campo acadêmico e, naturalmente, manifestam-se nas abordagens que os demais autores apresentam ao longo do livro. Dessa forma, há que se considerar este debate mais amplo acerca da própria trajetória do campo de investigação da Educação ao redor do mundo como cenário das análises que os autores empreendem. 
O primeiro capítulo do livro, desenvolvido por Gert Biesta, enfrenta questões cotidianas que, a priori, parecem mostrar-se de fácil resolução, porém, ao serem tomadas à análise cuidadosa, são capazes de revelar dilemas complexos que se colocam na base do fazer científico no âmbito da investigação social e educacional. De modo mais geral, a questão que Biesta enfrenta neste capítulo pode ser expressa da seguinte forma: como se pode encontrar o equilíbrio certo no engajamento com a teoria na pesquisa educacional? Esta interrogação emergiu da experiência de orientação de seus alunos e do acompanhamento das angústias destes estudantes quando se deparavam com o exercício de dialogar com a teoria já existente e avançar teoricamente por meio de suas próprias pesquisas. O autor promove, a partir do enfrentamento da questão, uma crítica à perspectiva utilitarista da investigação, a qual evidencia a geração de conhecimentos puramente técnicos e de tecnologia como o fim último de toda e qualquer ação investigativa. Ultrapassando o fetichismo do controle e da utilidade, Biesta defende que a pesquisa educacional deve ser emancipatória à medida que é capaz de proporcionar aos atores sociais e educacionais mais e melhores oportunidades para seu próprio julgamento, tomada de decisão e ação - Michel Foucault, Paulo Freire e Jacques Rancière são elencados nestas reflexões em função de seus contributos para pensar a relação saber-poder, a emancipação à educação bancária e a igualdade, respectivamente.

Logo depois, Nair Azevedo, Teresa Gonçalves e Mariana Gaio Alves trazem um capítulo que consegue transportar o leitor para a realidade da qual falam: as Ciências da Educação em Portugal. As dificuldades dos doutorandos em lidar com as questões de teoria são tomadas à análise na tentativa de demonstrar as potencialidades de estratégias que buscam enfatizar o pensamento crítico e reflexivo sobre o fazer investigativo para educar os próprios pesquisadores em formação. As características próprias do campo das Ciências da Educação, com especial ênfase à multirreferencialidadee à própria diversidade de percursos dos seus agente e áreas de diálogo, ganham espaço significativo na discussão empreendida por estas autoras e acabam por auxiliar no debate em torno das dificuldades em teorizar em Educação.

Mais uma realidade é apresentada ao leitor no terceiro capítulo do livro, estamos a falar da realidade espanhola, mais especificamente o caso do doutoramento oferecido pelo Departamento de Teoria e História da Educação e Pedagogia Social da Universidade de Sevilha. Trata-se do texto de Antonio Bernal Guerrero, que traz uma discussão bastante frutífera acerca das tradições de pesquisa em Educação que sustentam as diferentes denominações que recebeu [e ainda recebe atualmente] ao redor do mundo e, sobretudo, como 
as diferentes tradições implicam uma multiplicidade de formas de teorizar os fenômenos educativos. Uma análise quanti-qualitativa das teses de doutoramento defendidas no programa supracitado sustenta a argumentação em torno das especificidades espanholas quanto ao uso da teoria no pensamento educacional. $\mathrm{O}$ autor demonstra ainda - em diálogo com o próximo capítulo do livro - como a Espanha tem lidado com tal multiplicidade por meio da disciplina "Teoria da Educação" e sua capacidade de interligar o enredo disciplinar das Ciências da Educação. Gurrero defende que esta disciplina, ao compor o rol de matérias dos cursos da área da Educação em universidades espanholas, contitui-se em uma disciplina-chave para promover a articulação das diferentes ciências e perspectivas que compõem o domínio da Educação e, desse modo, acaba por contribuir para a superação da fragmentação do conhecimento agravada pelo maior desenvolvimento e hiperespecialização do saber acadêmico.

O capítulo de Joaquín García Carrasco, que encerra esta obra, é responsável por levantar um debate sobre a complexidade e a multidimensionalidade do fenômeno educativo à luz das implicações das neurociências cognitivas e da biologia evolutiva. Para o autor, se podemos tomar o conceito de "evolução" como unificador para toda a Biologia, podemos também tomar o conceito de "educação" - ou mesmo "formação" - como aquele mais unificador das Ciências Humanas e Sociais e, ainda, como uma espécie de ponte onde as humanidades e as Ciências da Vida se encontram. As reflexões unificadoras de Carrasco possuem lastro no cenário das investigações na área da Educação e na problemática da pulverização dos conhecimentos gerados a partir de tais investigações, para contornar esta problemática, a cooperação seria a chave mais indicada, segundo o autor: muitos elementos do quebra-cabeça dos fenômenos educativos encontram-se espalhados como resultado de diversos campos do conhecimento, somente um esforço cooperativo seria capaz de construir um panorama integrado de saberes.

De modo geral, pode-se afirmar que o leitor vai se deparar com uma argumentação encadeada e sólida na defesa de um uso mais consciente da teoria nas pesquisas educacionais. Diria ainda que este uso mais consciente é posposto por todos os autores que compõem esta obra à medida que eles conferem destaque à importância de se compreender as especificidades da área da Educação. A gênese desta área comoespaço acadêmico, as disciplinas ou áreas do conhecimento que historicamente têm contribuído para pensar os fenômenos educativos, bem como a singularidade de cada instituição, região ou país no que 
toca ao desenvolvimento do campo da Educação constituem, pois, aspectos fundamentais dos sabores e dissabores de fazer parte e de pesquisar em Educação.

O vigor do livro e de seus capítulos está, justamente, em sua capacidade de provocar o leitor a pensar e repensar o universo da Educação em ambiente acadêmico, seja esse leitor um estudante de doutoramento ou mesmo um pesquisador já estabelecido no campo cicntífico. As questões que os autores enfrentam poderiam ser colocadas para qualquer sujeito que vivencia o cotidiano das investigações acadêmicas, por isso, o que torna esta obra um texto necessário é justamente o enfrentamento de questões que, geralmente, são tratadas como elementos já resolvidos na atividade acadêmica, porém, quando interrogados fazem emergir vicissitudes e dilemas que enfrentamos nas pesquisas em geral, e na pesquisa em Educação de forma bastante específica. Nesse sentido, penso que os leitores que participam do jogo acadêmico no espaço da Educação certamente se identificarão com os dilemas e questões discutidas pelos autores, visto que elas se fazem imperativas quando se desenvolve uma investigação nesta área.

Além disso, outro fato merece destaque neste aspecto relacionado à identificação do leitor com as discussões que a obra traz, a saber: a emergência dos textos. Absolutamente todos os capítulos possuem sua gênese na prática universitária de orientação de estudantes da pós-graduação, ou seja, o livro ultrapassa as barreiras ensaísticas, por um lado, e as barreiras de apresentação de uma pesquisa específica, por outro. Tratam-se de discussões que, por nascerem do cotidiano dos professores investigadores em questão, tocam em aspectos do senso prático do métier do pesquisador em Educação ou em Ciências da Educação (no caso europeu). E, portanto, os debates travados ao longo das páginas deste livro possuem sentido e direção de desconstruir as certezas acerca do processo investigativo e propor uma reflexão sobre a própria doxa desta área.

As diferentes realidades apresentadas ao longo dos capítulos acabam por proporcionar ao leitor uma leitura concomitantemente comparada e aprofundada em torno das questões sui generis do campo acadêmico da Educação. As tensões e contradições que historicamente desafiam os pesquisadores da área da Educação emergem dos debates empreendidos pelos autores. Com particular atenção à questão da teorização nesta área, estes autores não fogem ao debate pantanoso em torno das dificuldades que enfrentam nos seus cotidianos de trabalho no ensino superior e, a partir de distintas abordagens, perspectivas, tradições e realidades, 
acabam por contribuir com a tarefa de situar as discussões contemporâneas sobre a Educação, sobre a pesquisa em Educação e sobre a teoria educacional. Ademais, os exercícios de pensar os desafios que se colocam no próprio trabalho do pesquisador movimentam a obra e podem movimentar reflexões outras nos potenciais leitores, dessa forma, contribuir para uma autorreflexãodo campo acadêmico ligado à Educação, como área de investigação, traduz um dos efeitos deste livro.

\section{Referências}

BERGER, G. A investigação em educação: modelos sócio-epistemológicops e inserção institucional. Revista de Psicologia e de Ciências da Educação, 314, 23-26, 1992.

BIESTA, G. J. J. Disciplines and theory in the academic study of education: A comparative analysis of the Anglo-American and Continental construction of the field. Pedagogy, Culture \& Society, 19(2), 2011, p. 175-192.

ESTRELA, A. Pedagogia, ciência da educação? Porto: Porto Editora, 1992.

FURLONG, J.; LAWN, M. (Eds.). Disciplines of education: their role in the future of education research. London: Routledge, 2011.

GATTI, B. A. A construção da pesquisa em educação no Brasil. Brasília: Plano Editora, 2002. (Série Pesquisa em Educação).

Recebido em: 23/10/2016

Aprovado para publicação em: 07/02/2017

Publicado em: 27/04/2017 